\title{
El mito como clave de lectura del pensamiento político de Gramsci desde la inmanencia
}

\section{The myth as a key to read Gramsci's political thought from immanence}

\author{
ALFONSINA SANTOLALLA \\ Universidad Nacional de Córdoba
}

Recibido: 11/02/2019

Aceptado: 05/03/2019

\section{RESUMEN}

En el presente trabajo nos abocaremos a analizar el concepto de mito que aparece en los Cuadernos de la cárcel de Gramsci. Consideramos que este concepto - proveniente del desarrollo teórico-político de uno de los interlocutores de Gramsci, Georges Sorel-constituye una clave para rastrear qué significa la construcción de una «nueva» inmanencia en la obra de Gramsci. Nos interesa explorar la posibilidad de que la inmanencia en Gramsci permita complejizar el proyecto gramsciano de construcción de una filosofía de la praxis, para la cual el mito se vuelve central.

\section{PALABRAS CLAVE}

GRAMSCI; MITO; INMANENCIA; POLÍTICA; PRAXIS.

\begin{abstract}
In this paper we will work on an analysis of the concept of myth, such as it appears in Gramsci's The prision notebooks. We consider that this particular concept-coming from the theoreticalpolitical development of one of Gramsci's interlocutors, Georges Sorel- constitutes a key to
\end{abstract}


trace what is the meaning of the construction of a «new» immanence in Gramsci's work. We are interested in exploring the possibility that immanence in Gramsci could allow the project of building a philosophy of praxis to be more complex than we think, and that for this, the concept of myth becomes essential.

KEY WORDS

GRAMSCI; MYTH; IMMANENCE; POLITICS; PRAXIS.

\section{INTRODUCCIÓN}

HaCE ya varias dÉCADAs que la filosofía lee a Gramsci como uno de los puntos de inflexión fundamentales para la historia y el desarrollo del marxismo. Los Cuadernos de la Cárcel -una obra asistemática, atravesada por la práctica política activa y un contexto altamente hostil- contienen una fuerte reformulación conceptual de muchos elementos que la tradición marxista en general no estaba cuestionando, y, a la vez, una investigación crítica y transversal a distintas tradiciones filosóficas. De esta forma, Gramsci inaugura nuevos problemas y perspectivas para leer a Marx, que hasta hoy abren puertas para el abordaje crítico del legado marxista en particular y de la historia de la filosofía en general.

En el presente trabajo nuestro interés estará centrado en abordar -al menos en parte- una de las reconfiguraciones conceptuales que Gramsci operó en su obra. Nos abocaremos a analizar el concepto de mito que aparece en los Cuadernos y su relación con la construcción gramsciana de una «nueva» tradición de la inmanencia. Es decir, a partir del estudio del concepto de mito -que Gramsci toma en gran parte de Georges Sorel-, buscamos rastrear qué significa la inmanencia en la obra de Gramsci, entendiendo que inmanencia es un término que ha nombrado diferentes desarrollos filosóficos a lo largo de la historia y que no puede pensarse sólo en torno a la construcción de una única tradición. Nos interesa explorar la posibilidad de que la inmanencia en Gramsci permita, por un lado, mostrar el contenido político de la filosofía de Marx -a partir de su análisis de la idea de la terrenalidad del pensamiento presente en las Tesis sobre Feuerbach-; pero además, por otro lado, que permita complejizar el proyecto gramsciano de construcción de una filosofía de la praxis, para la cual el mito se vuelve central.

Buscamos específicamente identificar cómo la perspectiva de la inmanencia aportó a construir la filosofía de la praxis que Gramsci desarrolla en los Cuadernos de la cárcel. En particular, queremos explorar la idea de que el concepto gramsciano de mito es el que condensa la relación entre teoría y práctica que se habilita a partir de incorporar la perspectiva de la inmanencia. 
Analizaremos el desarrollo de dicho concepto a partir de la lectura de los $\mathrm{Cua}$ dernos de la cárcel guiándonos por las hipótesis de que es la perspectiva de la inmanencia la que le permite a Gramsci construir una filosofía de la praxis, y de que el concepto de mito puede mostrar cuáles son las consecuencias de esa operación en términos más bien prácticos y políticos.

Para llevar adelante lo mencionado, en primer lugar, haremos un recorrido por los elementos que componen al concepto de mito en los Cuadernos, y desarrollaremos en especial los puntos que lo relacionan directamente con la perspectiva de la inmanencia que adopta Gramsci en su obra. En segundo lugar, haremos foco en la discusión que Gramsci entabla con Georges Sorel en torno al concepto de mito, repasando los orígenes vitalistas de las reflexiones sorelianas al respecto, y desarrollando cuáles son las implicancias prácticas y políticas de que Gramsci piense al mito desde la inmanencia. Y, en tercer lugar, elaboraremos conclusiones que den cuenta de la importancia del concepto de mito en particular y de la perspectiva de la inmanencia en general para el desarrollo de la filosofía de praxis en Gramsci.

\section{EL MITO: EL MOMENTO POLÍTICO DE LA INMANENCIA}

El concepto de mito, como desarrollaremos con más detalle en el siguiente apartado, aparece utilizado por Georges Sorel ${ }^{1}$-a partir de la influencia de la filosofía bergsoniana- con el sentido de ser expresión de una voluntad colectiva que resulta intocable para la razón, y que tiene el poder de mover la acción de un pueblo. Gramsci toma este concepto pero lo reinterpreta: a partir de la lectura de El Príncipe de Maquiavelo, el concepto original queda transformado, adquiriendo otra complejidad. En este apartado nos proponemos hacer un análisis de los fragmentos de los Cuadernos de la cárcel en los que El Príncipe de Maquiavelo aparece como un libro que, combinado con la reinterpretación que hace Gramsci de la inmanencia, permite la aparición de un mito capaz de afectar a la voluntad colectiva de un pueblo. El problema central del apartado consiste en vincular la idea de inmanencia desarrollada en Gramsci -que implica cambios respecto a lo heredado de otras tradiciones-con el concepto de mito al que da lugar. Creemos que comprender el lugar ocupa la inmanencia tanto en el origen como en el desarrollo del concepto de mito en Gramsci permitirá avanzar en la comprensión de las implicancias teóricas y prácticas de la postura de Gramsci en torno a las discusiones políticas en las que se inscribe.

Maquiavelo es un punto clave en los Cuadernos de la cárcel porque es en el análisis de El Príncipe que Gramsci reconoce de forma primitiva una idea que luego será la base de la teoría de la hegemonía: la idea de que el poder se construye sobre una realidad material y que, a la vez, su legitimidad

1 Cf. Sorel, G. 1978: Reflexiones sobre la violencia. Buenos Aires: La Pléyade. 
se construye en el discurso. En definitiva, de que las dos dimensiones de la verdad, la teórica y la práctica, están íntegramente relacionadas. La verdad, en el Maquiavelo de Gramsci, se torna necesariamente ideológica, y es, por eso, capacidad de transformación.

Fabio Frosini ${ }^{2}$ explica, en este respecto, el cambio que se opera en Gramsci desde la confección del Cuaderno 8 en 1931 hasta que escribe el Cuaderno 13 en 1933. En el Cuarderno 8, Gramsci -en su primera mención al Príncipe-hace énfasis en el realismo político de Maquiavelo, en un doble sentido: señalando que el análisis técnico que hace de la política puede ser usado por todas las clases sociales y no sólo por los intelectuales, y además que lo inscribe en la coyuntura de su tiempo. En el Cuaderno 13, en cambio, Gramsci profundiza en la idea de Maquiavelo como «filósofo de la praxis» porque, en el final de $E l$ Príncipe, por medio de una operación mítica, el Príncipe se identifica con el pueblo, acercando su condición de intelectual a la realidad práctica, por medio de un llamado a la acción política.

El carácter fundamental del Príncipe es precisamente el de no ser un tratado sistemático, sino un libro «vivo» en el que la ideología se convierte en «mito», o sea en «imagen» fantástica y artística entre la utopía y el tratado escolástico, en el que el elemento doctrinal y racional se personifica en un «condottiero» que presenta plásticamente y «antropomórficamente» el símbolo de la «voluntad colectiva». ${ }^{3}$

De esta forma, es en esa segunda caracterización del Príncipe de Maquiavelo que Gramsci introduce el concepto de mito en los Cuadernos. Gramsci reconoce en Maquiavelo una identificación entre conciencia y acción, entre racionalidad y voluntad. Observa que Maquiavelo es capaz de hacer de su análisis técnico de la práctica política una herramienta para el pueblo, pero que es por medio de la mitificación de la figura de un Príncipe abstracto que sobre el final del libro se identifica con la voluntad popular en una exhortación a la acción. Todo esto resulta central para el desarrollo de la filosofía de la praxis de Gramsci porque muestra cómo la teoría aparece y se desarrolla con sentido sólo en la medida en que haya identificación con alguna imagen que interpele al pueblo para la acción, es decir, en que haya un sujeto histórico con posibilidades de devenir revolucionario a partir de su auto-identificación con alguna fantasía, ${ }^{4}$ a partir de la mítica toma de conciencia que les permiten los «libros vivos», como lo es El Príncipe.

$2 C f$. Frosini, F., «Democracia, mito y religión: El Maquiavelo de Gramsci entre Georges Sorel y Luigi Russo», en R. Salatini, M. Del Roio (Organizadores), Reflexões sobre Maquiavel. São Paulo: Cultura Acadêmica, 2014, pp. 173-193.

3 Gramsci, A. 1981: Cuadernos de la cárcel. México D.F: Era, C13 §1.

4 En torno a cómo se complementan entre las consecuencias teóricas y los aportes 
El Príncipe de Maquiavelo podría ser estudiado como una ejemplificación histórica del «mito» soreliano, o sea de la ideología política que se presenta no como fría utopía ni como doctrinario raciocinio, sino como «fantasía» concreta que actúa sobre un pueblo disperso y pulverizado para suscitar y organizar su voluntad colectiva. El carácter utópico del Príncipe está dado por el hecho de que el «príncipe» no existía realmente, históricamente, no se presentaba al pueblo italiano con características de inmediatez histórica, sino que era él mismo una abstracción doctrinaria, el símbolo del jefe en general [...]..$^{5}$

Para Gramsci, hacer uso del concepto de mito es central para el desarrollo de su filosofía de la praxis. Caracterizar al mito como «fantasía», como una especie de término medio -imaginario y, por eso, posible-entre utopía y tratado doctrinal, permite pensar en una figura conceptual que sintetiza a la voluntad y a la razón, y por tanto -indirectamente- a la praxis y a la teoría. El Príncipe es un mito, y el mito es la forma en que la teoría puede intervenir en la realidad. Para Gramsci, producir teoría consiste en dar lugar a mitos que puedan actuar sobre pueblos pulverizados y divididos para organizar su voluntad colectiva. El mito pertenece al ámbito de la fantasía y por eso puede dar lugar a lo no existente aún en la realidad -es decir, puede dar lugar a un futuro posible como algo presente, a una promesa- en una síntesis entre teoría política y afección de voluntades colectivas que se sienten interpeladas por el mito o la imagen fantástica que se logre construir.

Consideramos que, así definido, el concepto de mito que desarrolla Gramsci está directamente ligado a la «nueva» inmanencia que busca también construir en los Cuadernos. Como indica Frosini, ${ }^{6}$ Gramsci se aparta de la idea moderna de inmanencia como categoría metafísica para pensar a la inmanencia como «terrenalidad del pensamiento»-a partir de la lectura de las Tesis sobre Feuerbach-, como «experiencia», como identificación entre teoría o pensamiento y acción política o praxis. El mito, como síntesis fantástica entre razón y voluntad, es inmanente en este sentido, y reconfigura las posibilidades que tiene el marxismo para pensar a la práctica política. En el apartado final de este trabajo abordaremos con más detalle la importancia de esta redefinición que hace Gramsci de la inmanencia -y, por tanto, de la introducción del con-

políticos a partir de la relación entre el partido político y el orden de la fantasía presente en la interpretación gramsciana de Maquiavelo, $C f$. Thomas, P. D., "Gramsci's Maquiavellian Metaphor. Restaging The Prince», en F. Frosini, F. Del Lucchese, V. Morfino (editores), The Radical Maquiavelli: Politics, Philosophy and Lenguage. Leiden: Brill, 2015.

5 Ibidem.

6 Cf. Frosini, F. 2009: Da Gramsci a Marx. Ideologia, verità e politica. Roma: DeriveApprodi. 
cepto de mito como central para la política- para el desarrollo de su filosofía de la praxis. Pero antes, a continuación, ingresaremos en la discusión que Gramsci entabla con Sorel al tomar -y a la vez criticar- su concepto de mito, y analizaremos cómo el desplazamiento de los orígenes vitalistas del mito y el acercamiento a una idea de mito más bien inmanente se traduce en el cuestionamiento práctico-político que Gramsci hace del espontaneismo de Sorel.

\section{LA TRANSFORMACIÓN DEL MITO SORELIANO EN MITO PARA LA PRAXIS INMANENTE}

Georges Sorel, en sus Reflexiones sobre la violencia, define al mito como un sistema de imágenes y representaciones que se caracterizan por motivar a los hombres a la acción, a que constituyan fuerzas históricas. La idea en general consiste en que la existencia de las revoluciones y las grandes movilizaciones sociales no se explica como un mero traspaso inmediato de una ideología teórica al plano de la acción, sino que es necesario que una serie de representaciones del ámbito de lo «imaginario» articulen las ideas con las acciones que éstas necesiten para efectivizarse en la realidad.

[...] los hombres que figuran en los grandes movimientos sociales imaginan su acción próxima en forma de combates, aseguradores del triunfo de su causa. Y propuse denominar mitos a dichas construcciones, cuyo conocimiento ofrece tanta importancia para el historiador; la huelga general sindicalista y la revolución catastrófica de Marx son mitos. ${ }^{7}$

En relación al análisis del concepto soreliano de mito, en este apartado nos interesa mencionar la recuperación explícita que hace Sorel de algunos elementos de la filosofía de Henry Bergson. En ese momento -a principios de siglo XX-Bergson permitía pensar al mundo como un constante un impulso vital que afecta a la materia, dando como resultado dos niveles de «duración» -uno interno y otro externo- de la realidad, en los cuales estamos inscriptos de manera inmanente como seres humanos desde nuestra condición de cuerpos, pero también de conciencias. ${ }^{8}$ En la ontología bergsoniana, toda acción crea «mundos artificiales» modificando todas las cosas, pues no hay un movimiento mecánico de la materia, sino una «evolución» de la vida en general, en función de un ritmo del que los hombres formamos parte de manera creativa gracias a la capacidad innovadora de nuestra inteligencia. Sorel considera todo esto $\mathrm{y}$, respecto a nuestra capacidad de «crear mundos», dice: «Semejantes mundo artificiales desaparecen por lo general de nuestro espíritu sin dejar recuerdos; mas cuando hay masas apasionadas, puede entonces describirse un cuadro, que

7 Sorel, 1978, p. 23.

8 Cf. Bergson, H. 2007: La evolución creadora. Buenos Aires: Cactus. 
constituye un mito social. $\rangle^{9}$ En eso consiste, al menos hasta donde entendemos, el origen bergsoniano del concepto de mito que introduce Sorel.

Por otra parte, nos resulta importante señalar aquí que Sorel cree necesario distinguir claramente mito de utopía. En las Reflexiones señala que los mitos no pueden ser «refutados» lógicamente, pues no surgen como formulación racional teórica, sino que se identifican con lo que los hombres sienten y, por tanto, lo que los lleva a la acción. La utopía, en cambio, como idea de posible constitución social, puede ser refutada en tanto no está comprometida su validez con ningún sentimiento popular movilizador, sino sólo con su validez lógica y su verosimilitud histórica. Ambas representaciones pueden mezclarse, pero no se identifican. Esta distinción le sirve a Sorel para explicar que el mito tiene capacidad constructiva sólo en el sentido en que moviliza en un momento determinado a la voluntad popular, y no en función de las ideas, fines o planes estratégicos que lo compongan.

Nos arriesgamos a decir que es una consecuencia de querer seguir las ideas de Bergson que Sorel ponga tanto énfasis en el carácter más instantáneo que progresivo que para él adquiere la temporalidad del mito. La distinción entre mito y utopía termina por señalar que la importancia del mito está en ser imagen movilizadora de sentimientos que logren una acción efectiva, aunque sea sólo momentánea. Además, en ese marco, Sorel resalta el carácter reaccionario que suelen tener las utopías, por querer imponer ciertos fines a la acción que no necesariamente se corresponden con el sentir popular. En clave bergsoniana, Sorel defiende una idea de mito que aparentemente sólo puede comprenderse a partir de las intuiciones de quienes se sienten interpelados por él, y que nada tiene que ver -al menos necesariamente- con posibles planes de construcción política en sintonía con la acción posibilitada. Y es que Bergson ${ }^{10}$ sostiene una idea de intuición -un término medio entre instinto e inteligencia- que permite comprender la «singularidad» de las cosas -pues estaría, dentro de nuestras capacidades de comprender el mundo, en un nivel medio entre las dos «duraciones», la externa y la interna, que para Bergson tiene la realidad. Es por todo esto que Sorel concluye que, al ser el mito la herramienta de la política popular más importante por su capacidad de plasmar en acciones los sentimientos del pueblo, es la espontaneidad la forma que deben adquirir las principales acciones políticas del movimiento revolucionario, y la «huelga general» es la acción política por excelencia.

A partir de la hipótesis de que el concepto de mito presente en Gramsci va de la mano con la adopción de una «nueva» perspectiva de la inmanencia,

9 Sorel, op. cit., p 50.

$10 C f$. Bergson, H. 2006: Materia y memoria: ensayo sobre la relación del cuerpo con el espíritu. Buenos Aires: Cactus. 
entendemos que en su superación de Sorel y de ese primer concepto de mito, marca también una distancia respecto a la interpretación soreliana de Bergson, lo cual se traduce también en su crítica al concepto de mito soreliano.

[...] para Sorel el mito no se personificaba en el sindicato, como expresión de una voluntad colectiva, sino en la acción práctica del sindicato y de la voluntad colectiva ya organizada y operante, acción práctica, cuya realización máxima habría debido ser la huelga general, o sea una «actividad pasiva» por así decirlo, todavía no pasada a la fase «activa o constructiva». ${ }^{11}$

Para Gramsci, el que Sorel se quede en la idea de que sólo una acción momentánea y espontánea de la voluntad popular es legítimamente una acción motivada por el mito político para la revolución, es un problema grave en varios sentidos. En primer lugar, porque eso dejaría la capacidad «creativa»o «constructiva» del mito en una fase excesivamente primitiva, llegando al punto de reducir la capacidad del mito de devenir transformación activa de la realidad, al sólo hecho de poder suscitar una «actividad pasiva», sin posibilidades de construcción política real. En segundo lugar, porque detrás de la «espontaneidad» de Sorel, opina Gramsci, hay un determinismo oculto, ya que se pretende que los impulsos espontáneos lleven por sí solos a un fin deseable. Y, finalmente, porque en esta concepción no tiene relevancia la discusión sobre un movimiento político con la madurez suficiente para encarar un proceso revolucionario que realmente construya la transformación de lo dado, pues para Sorel pensar los objetivos de la construcción progresiva de una nueva hegemonía en conjunto con el mito, es decir, introducir elementos «utópicos» (en sentido soreliano) en la acción movilizada míticamente, puede resultar reaccionario.

Por todo esto, para Gramsci es de central importancia explicitar que es el partido político, el «príncipe moderno»-como a menudo lo denomina-el único capaz de llevar adelante una reforma intelectual y moral para que la voluntad popular logre verse representada en una transformación de las condiciones reales de existencia material y cultural, y no en una mera acción espontánea. Es en este punto que Gramsci está marcando una diferencia política importante con Sorel. Podríamos decir, de alguna manera y desde nuestro punto de vista, que Gramsci toma distancia de una idea de mito basada en el concepto bergsoniano de intuición, y que si bien sigue apostando por una perspectiva de la inmanencia -como hacía también el vitalismo de Bergson- hay en Gramsci un desplazamiento respecto de la tradición de la inmanencia y la inauguración de una inmanencia de lo «terrenal» que le permite, en este punto, ampliar el concepto de mito. El ejemplo perfecto, según Gramsci, del concepto de mito, es El Príncipe de Maquiavelo, lo cual permite que incluya -además de la idea

11 Gramsci, op. cit., $\mathrm{C} 13 \S 1$. 
de que ciertas imágenes o representaciones en conjunto movilizan los sentimientos de los hombres- la convicción de que esas imágenes no sólo producen acciones, sino que construyen la realidad sobre la base de ideas. La dimensión creativa del mito que conceptualiza Gramsci señala la necesidad de que toda acción movilizada míticamente, si es que hablamos de mitos que sirven a la suscitación de acciones políticas revolucionarias y sostenibles en el tiempo, esté acompañada de un plan ideológico de organización en pos de transformar el mundo en función de los intereses del pueblo movilizado. Ese es el conflicto político que Gramsci establece con Sorel en su reconceptualización del mito, y que nos permite ver además la complejidad de su redefinición de la inmanencia -particularmente en lo que refiere al vitalismo bergsoniano.

\section{INMANENCIA PARA UNA FILOSOFÍA DE LA PRAXIS}

A modo de conclusión general, nos proponemos ensayar, a partir de los elementos abordados, un breve análisis de cómo la «nueva» perspectiva de la inmanencia adoptada por Gramsci aportó a la construcción de la filosofía de la praxis. Creemos que, a partir de las relaciones ya establecidas entre la inmanencia como «experiencia» en la que estaba pensando Gramsci y su reformulación del concepto soreliano de mito, es posible extraer o al menos imaginar con más claridad algunas consecuencias posibles de la filosofía de la praxis gramsciana en términos práctico-políticos.

Para Gramsci, pensar o construir una filosofía de la praxis significaba poder salirse del plano de lo estrictamente racional, para retomar la vitalidad y el carácter activo de un pueblo que permite convertirlo en una fuerza de transformación de la historia. Sostener una filosofía de la praxis implica comprender la constante contingencia a la que está sujeta la historia, y, por eso mismo, la permanente posibilidad de construir un nuevo orden de lo real, una nueva hegemonía. En este sentido, el concepto de mito se vuelve central para la construcción de una filosofía de la praxis. Ya que, si se entiende que hay una posibilidad permanente de transformar la realidad, es preciso atender a la relación directa que hay entre posibilidad - o promesa- $\mathrm{y}$ acto, $\mathrm{y}$, por tanto, a la dimensión mítica de la actividad política. ${ }^{12}$

Sintéticamente, podemos decir que la idea de filosofía de la praxis que busca pensar Gramsci consiste en la identificación entre praxis y verdad, y por eso se trata de un concepto que atraviesa directamente lo que Gramsci entiende por mito. El mito permite el acortamiento de la distancia entre «lo alto» $\mathrm{y}$ «lo bajo», entre las clases privilegiadas y las populares, e introduce la dimensión

12 Para un análisis más exhaustivo del sentido gramsciano de la filosofía de la praxis, $C f$. P. Sotoris, «The Laboratory of Philosophy. Gramsci and Althusser on Philosophy», Décalages: Vol. 2: Iss 1, 2016. 
de fe, de promesa, o utopía que permite entender cómo se moviliza la voluntad popular. Ésta se ve conmovida, interpelada, por ciertos símbolos, imágenes y representaciones que apelan a sus pasiones, lo cual permite que sea posible una acción colectiva -aunque no espontánea, sino que también existe cierta teoría operando en conjunto con la imagen- $\mathrm{y}$ una ulterior organización para la construcción política.

Como ya vimos, Gramsci, en la redacción de sus Cuadernos, se aleja progresivamente de cualquier rastro de una tradición moderna de inmanencia. Al identificar cómo se habían asociado los términos inmanencia y metafísica, Gramsci entiende que debe resignificar a la inmanencia en un sentido materialista (de «terrenalidad del pensamiento» en términos de Marx), para dar cuenta del potencial teórico del término. Inmanencia entonces es para Gramsci identificación entre teoría o pensamiento y acción política o praxis, y la filosofía de la praxis se vuelve, conceptualmente, una consecuencia -podríamos decir- directa de la adopción de una perspectiva de la inmanencia. A la vez, es posible observar cómo en los Cuadernos hay un trabajo de mutua definición entre el concepto de inmanencia y el de filosofía de la praxis.

El término «inmanencia» en la filosofía de la praxis tiene su significado preciso [...] La filosofía de la praxis continúa la filosofía de la inmanencia, pero la depura de todo su aparato metafísico y la conduce al terreno concreto de la historia. ${ }^{13}$

A nuestro parecer, son conceptos que se iluminan entre sí, y es claro que no puede comprenderse la complejidad de la filosofía de la praxis sin pensar en las implicancias de la adopción de una perspectiva de la inmanencia. Perspectiva que además permite la formulación del concepto de mito para dar cuenta de cómo las acciones políticas son suscitadas no sólo por de un plan ideológico de organización, ni tampoco sólo por promesas utópicas: pensar en términos de inmanencia permite hablar de mito como síntesis entre la voluntad de actuar y transformar realidades y el razonamiento téorico. Como vimos también, una perspectiva de la inmanencia arraigada al «terreno concreto de la historia», no implica aceptar un espontaneismo determinista. Inmanencia para Gramsci no es sólo que siempre hay vinculación de la praxis con aspectos del pensamiento racional, sino que además la teoría que se produce está siempre en contacto con la práctica, lo cual significa que siempre teoría, es práctica. Hablar de filosofía de la praxis es entender que toda filosofía es inmanente a la sociedad en la que se encuentra, y que por ende produce $-\mathrm{y}$ se produce porhegemonía; es reconocer el carácter político de la filosofía y de la realidad. Construir filosofía de la praxis es tomar las herramientas que brindan tanto la historia de la filosofía y el pensamiento político y las claves que brindan las

13 Gramsci, op. cit., C4, §17. 
experiencias políticas concretas: en ese marco, comprender cómo funciona el mito se vuelve fundamental. En síntesis, el mito resulta una clave de lectura ineludible para comprender las consecuencias políticas de la filosofía de la praxis construida por Gramsci.

\section{REFERENCIAS BIBLIOGRÁFICAS}

Sobre la sigla utilizada para citar los Cuadernos de la cárcel:

Al referirnos a la obra de Gramsci, Cuadernos de la cárcel, editada en México D.F por Era en 1981, utilizamos la modalidad de indicar el Cuaderno del que proviene la cita mediante la letra «C», y el apartado en particular en la que está contenida, por medio del símbolo §. Por caso, cuando nos referimos al apartado 16 del Cuaderno 7, citamos: Gramsci, 1981, C7, §16. De esta manera, la cita puede rastrearse en todas las ediciones -en cualquier idioma- provenientes de la edición crítica original de los Cuadernos a cargo del Instituto Gramsci de Turín (1975).

BERGSON, H. 2006: Materia y memoria: ensayo sobre la relación del cuerpo con el espíritu. Buenos Aires: Cactus.

___ 2007: La evolución creadora. Buenos Aires: Cactus.

FROSINI, F. 2009: Da Gramsci a Marx. Ideologia, verità e politica. Roma: DeriveApprodi.

____ , «Democracia, mito y religión: El Maquiavelo de Gramsci entre Georges Sorel y Luigi Russo», en R. Salatini, M. Del Roio (Organizadores), Reflexões sobre Maquiavel. São Paulo: Cultura Acadêmica, 2014, pp. 173-193.

GRAMSCI, A. 1981: Cuadernos de la cárcel. México D.F: Era.

SOREL, G. 1978: Reflexiones sobre la violencia. Buenos Aires: La Pléyade.

SOTORIS, P., «The Laboratory of Philosophy. Gramsci and Althusser on Philosophy», Décalages: Vol. 2: Iss 1, 2016.

THOMAS, P. D., «Gramsci's Maquiavellian Metaphor. Restaging The Prince», en F. Frosini, F. Del Lucchese, V. Morfino (Editores), The Radical Maquiavelli: Politics, Philosophy and Lenguage. Leiden: Brill, 2015.

Alfonsina Santolalla es egresada de la Universidad Nacional de Córdoba - Facultad de Filosofía y Humanidades. Miembro del Proyecto de investigación "El retorno de lo común: filosofía, crítica y práctica política" financiado en la Secretaría de Ciencia y Técnica de la Universidad Nacional de Córdoba

Línea de investigación:

Filosofía política contemporánea

Email: asn.713@gmail.com 
